\title{
Scientific approach for ozone absorption in blood during systemic indirect endovenous ozonetherapy
}

\author{
Jose Baeza-Noci', Rosa Pinto-Bonilla1, Leonor Contreras-Velasco², Manuel Gomez-Moraleda \\ ${ }^{1}$ NISA Virgen del Consuelo Hospital, Valencia, Spain, ${ }^{2}$ Sant Joan de Deu, Manresa (Barcelona), Spain, ${ }^{3}$ Medozono, Barcelona, \\ Spain
}

\section{ABSTRACT}

\section{(2) OPEN ACCESS}

\section{Citation}

Baeza-Noci J, Pinto-Bonilla R, ContrerasVelasco L, Gomez-Moraleda M. Scientific approach for ozone absorption in blood during systemic indirect endovenous ozonetherapy. $J$ Ozone Ther. 2018:2(3) doi: 10.7203/jo3t.2.3.2018.9611

\section{Academic Editor \\ Jose Baeza-Noci, \\ School of Medicine, Valencia University, SPAIN}

\section{Editor}

World Federation of Ozone Therapy, Bologna, ITALY

\section{Received}

March 2, 2017

\section{Accepted}

November 11, 2017

\section{Published}

December 15, 2018

\section{Intellectual Property}

Baeza-Noci J.

This is an open access article distributed under the terms of the Creative Commons Attribution License (CC BY 4.0), which permits unrestricted use, distribution, and reproduction in any medium, provided the original author and source are credited.

\section{Author Information}

jose.baeza@uv.es
Introduction. Reading reference ozone books from Dra. Menendez, Dra. Viebhan, Dra. Borrelli and Dr. Bocci, proper timing for mixing ozone in blood during autohemotherapy is not calculated in a scientific way, having only an estimation of it based on changes in the blood color, more related to oxygen absorption than on ozone itself.

Material and methods. We decided to reproduce a reduced model of great autohemotherapy or recently renamed as systemic indirect endovenous ozonotherapy (SIEVO) by the World Federation of Ozone Therapy - WFOT, using syringes to simplify the experiment. Our model consisted of a $20 \mathrm{~mL}$ syringe filled with $10 \mathrm{~mL}$ of blood withdrawn from healthy volunteers and mixed it gently but in controlled way with $10 \mathrm{~mL}$ medical ozone at different concentrations; after 5 and 8 seconds, the remaining gas was analyzed by an spectrophotometer based ozone detector to check the amount of ozone. Data were analyzed using a linear regression model.

Results. Results show that even for $60 \mathrm{mcgr} / \mathrm{mL}$ ozone concentration, 8 seconds is enough to let all ozone absorbed in blood.

Discussion and Conclusions. The experiment shows how quick ozone reacts with blood and claims for a trial with real SIEVO devices to achieve a real timing.

Keywords: Systemic indirect endovenous ozonotherapy, blood ozone

\section{Introduction}

Ozone therapy has developed for many years in a empirical environment. Unfortunately, it was rejected from conventional medicine in the 30s and its use remained limited to natural medicine [1,2]. Since the $80 \mathrm{~s}$, these techniques based on ozone gas administration have been progressively introduced in orthodox medicine thanks to scientifically designed studies [3]. However, even now that we have solid evidence of the efficacy of ozone in some pathologies, the king of the ozone systemic approach, the SIEVO technique, still has a big caveat in it: a scientific timing for the mixing procedure and a fixed procedure for this mixing process. The timing proposed for this technique range from $1[2,3]$ to 5 [4] minutes.

Due to these facts, we decided to develop an experiment to settle a standard mixing technique and a minimum time of mixing, so every doctor will clearly know how to perform a SIEVO procedure. 
Other technical aspect, like the use of crystal or ozone resistant plastic bags or bottles is now a futile discussion, when some of the late ones have been homologated by the European Medicines Evaluation Agency (EMEA) as medical devices for ozone therapy and have got the CE mark. The use of single or double tube devices is still not clear and should also be scientifically studied by manufacturers.

\section{Materials and methods}

In a standard SIEVO, equal amounts of blood from the patient and medical ozone are mixed in a bottle or plastic bag resistant to ozone. As it is impossible to measure the ozone dissolved in blood during a SIEVO because of its enormously quick reaction with blood components [3], we decided to measure the ozone in the remaining gas. The timing we proposed for this technique ranged from 10 to 20 seconds based on the ozone quick reaction with blood components. According to this timing, the ozone decomposed into oxygen during this time is negligible, as ozone autodecomposes at a rate of $2 \%$ per minute at room temperature $\left(20-24^{\circ} \mathrm{C}\right)[1]$.

In order to avoid withdrawing a great amount of blood from a great numbers of volunteers, we designed a reduced model of the SIEVO procedure by using a $20 \mathrm{~mL}$ siliconized syringe (Luer BBRAUN Omnifix, Melsungen, Germany) currently used for ozone injections. We filed it with $10 \mathrm{~mL}$ of blood previously collected from 5 volunteers (see details below) in $60 \mathrm{~mL}$ syringes previously anticoagulated with $6 \mathrm{~mL}$ of sodium citrate $3,13 \%$ each, so we had 6 samples of $10 \mathrm{~mL}$ from each volunteer. To fill the $20 \mathrm{~mL}$ syringe, first with blood and later with $10 \mathrm{~mL}$ of medical ozone, we used an ozone resistant three-way stopcock (BBRAUN Discofix, Melsungen, Germany). To produce the medical ozone, we used a Humazon Promedic from HUMARES $\mathrm{GMBH}$, Bruchsal, Germany. The ozone generator was firstly calibrated by an ozone measuring spectrophotometer (OMS) Ozone Analizer BMT 964 from BMT MESSTECHNIK, Berlin, Germany, that we also used to measure the ozone concentration in the remaining gas after the mixing procedure. We decided to use a $20 \mathrm{~mL}$ syringe because the OMS needed at least $5 \mathrm{~mL}$ of gas to perform a good measure, so $10 \mathrm{~mL}$ of remaining gas to analyze after the mixture will produce an exact measurement. Once performed the mixing technique, we measured the remaining gas in the syringe to get to know how much of ozone remained and calculate the ozone that has dissolved in the blood by injecting it into the OMS, procedure that takes 3 seconds.

The first step was to decide a method for mixing that could be used also in standard bottles or bags for ozone. We withdraw $60 \mathrm{~mL}$ of blood from one of the volunteers and used one sample of $10 \mathrm{~mL}$ (named A) with a soft twisting mixing maneuver and other sample of $10 \mathrm{~mL}$ (named B) with a maneuver (Fig.1) that consisted of turning $135^{\circ}$ the syringe from a vertical position to a declined position, taking one second to perform this movement without shake; immediately, we turned back the syringe to a vertical position during one more second and repeated this procedure for the desired time. We used $60 \mu \mathrm{gr} / \mathrm{mL}$ medical ozone for both samples ( $A$ and $B$ ). As we had no approximate idea of the time of mixture, we used a 15

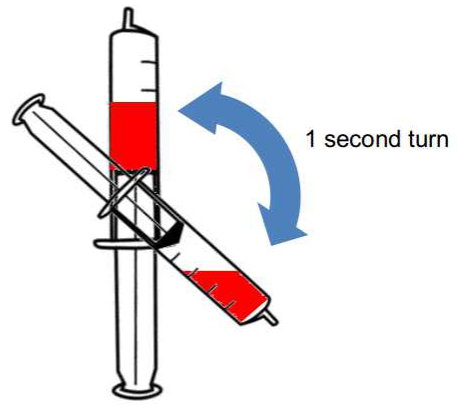

Figure 1. Mixing maneuver. 
seconds time (plus 3 more seconds to introduce the remaining gas into the OMS). The result of this first approach was that sample $A$ had, in the remaining gas, an ozone concentration of $6,5 \mu \mathrm{gr} / \mathrm{mL}$ and sample $B$ had a concentration of ozone of zero $(0 \mu \mathrm{gr} / \mathrm{mL})$. We realized of the great importance of the mixing procedure and also of the short time of mixing time needed. We used this last method of mixing, shown in figure 1, during the rest of the experiment. Foam or bubbles never appeared.

We then decided to use 3 more samples of $10 \mathrm{~mL}$ from the rest of the $60 \mathrm{~mL}$ remaining, using the same ozone concentration and mixing intervals of 5,10 and 15 seconds (real times of 8,13 and 18 seconds). For the 10 and 15 seconds samples, the remaining gas had no ozone. Due to the short time of mixing, ozone decomposed into oxygen is negligible.

The last step was to confirm these results with a bigger sample, different concentrations and a mixing time under 10 seconds (5 and 8 seconds). We tested 20,40 and $60 \mu \mathrm{gr} / \mathrm{mL}$ concentrations as they are the most frequently used ones. $60 \mathrm{~mL}$ of blood were withdrawn from 5 healthy volunteers in two different cities. Age ranged from 31 to 44 years. 2 males and 3 females. From each volunteer, we got 6 samples of $10 \mathrm{~mL}$ of blood. We mixed 2 samples with each concentration, following the mixing procedure described above, so we got 10 different samples of $10 \mathrm{~mL}$ for each concentration.

We used the free software QtiPlot version 0.9.8.9 for statistical analysis under Ubuntu 14.04 operative system.

\section{Results}

Table 1 compiles the data collected referred in the previous paragraph.

Table 1

\begin{tabular}{|c|c|c|c|c|c|c|c|c|c|}
\hline & \multicolumn{9}{|c|}{ BASE OZONE CONCENTRATION, $\mu \mathrm{g} / \mathrm{ml}$. } \\
\hline & \multicolumn{3}{|c|}{60} & \multicolumn{3}{|c|}{40} & \multicolumn{3}{|c|}{20} \\
\hline & \multicolumn{9}{|c|}{ Mixing time (seconds) } \\
\hline Volunteer & 0 & 5 & 8 & 0 & 5 & 8 & 0 & 5 & 8 \\
\hline 1 & 60 & 7 & 0,2 & 40 & 2,8 & 0 & 20 & 0,1 & 0 \\
\hline 2 & 60 & 8,6 & 0,2 & 40 & 2,4 & 0 & 20 & 0,1 & 0 \\
\hline 3 & 60 & 7,4 & 0,3 & 40 & 2,6 & 0 & 20 & 0,1 & 0 \\
\hline 4 & 60 & 5,5 & 0,1 & 40 & 2,5 & 0 & 20 & 0,2 & 0 \\
\hline 5 & 60 & 4,8 & 0,1 & 40 & 2,5 & 0 & 20 & 0,1 & 0 \\
\hline $1 \mathrm{bis}$ & 60 & 6,3 & 0,2 & 40 & 2,7 & 0 & 20 & 0,2 & 0 \\
\hline 2bis & 60 & 8,1 & 0,2 & 40 & 2,3 & 0 & 20 & 0,2 & 0 \\
\hline 3bis & 60 & 7 & 0,3 & 40 & 2,4 & 0 & 20 & 0,1 & 0 \\
\hline 4bis & 60 & 3,9 & 0,1 & 40 & 2,3 & 0 & 20 & 0,2 & 0 \\
\hline 5 bis & 60 & 9,8 & 0,3 & 40 & 2,6 & 0 & 20 & 0,1 & 0 \\
\hline edian & & 6,84 & 0,20 & & 2,51 & 0,0 & & 0,13 & 0,00 \\
\hline D. & & 1,78 & 0,08 & & 0,17 & 0,0 & & 0,04 & 0,00 \\
\hline
\end{tabular}


Figures 2 and 3 show that for 20 and $40 \mu \mathrm{gr} / \mathrm{mL}$ concentration, there is almost no ozone in the remaining gas after 5 seconds of mixing. For $60 \mu \mathrm{gr} /$ $\mathrm{mL}$ (Figure 4), 99.67\% has dissolved after 8 seconds.

\section{Ozone absortion}

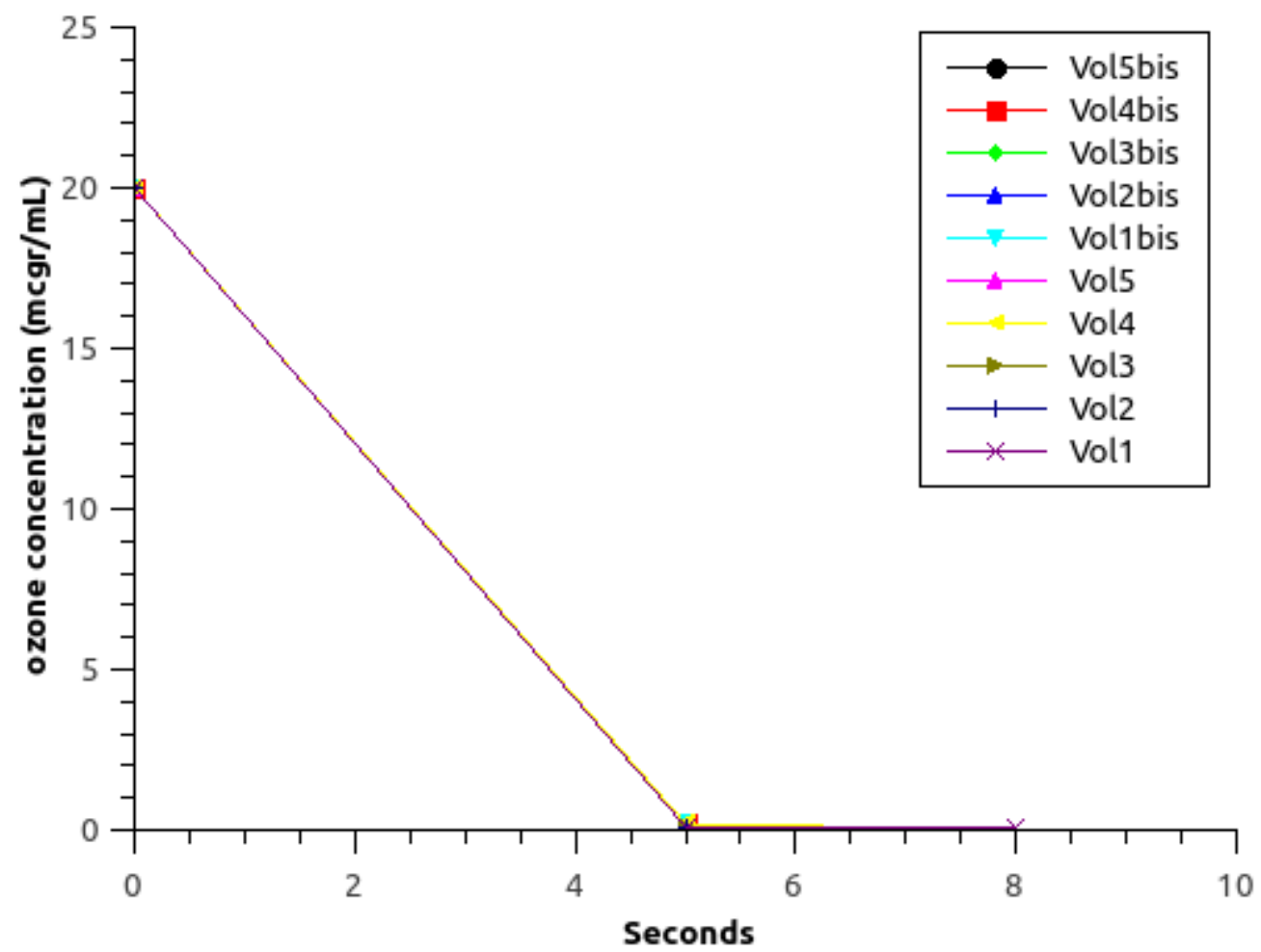

Figure 2. Ozone absortion for $20 \mu \mathrm{gr} / \mathrm{mL}$ of ozone concentration.

\section{Ozone absortion}

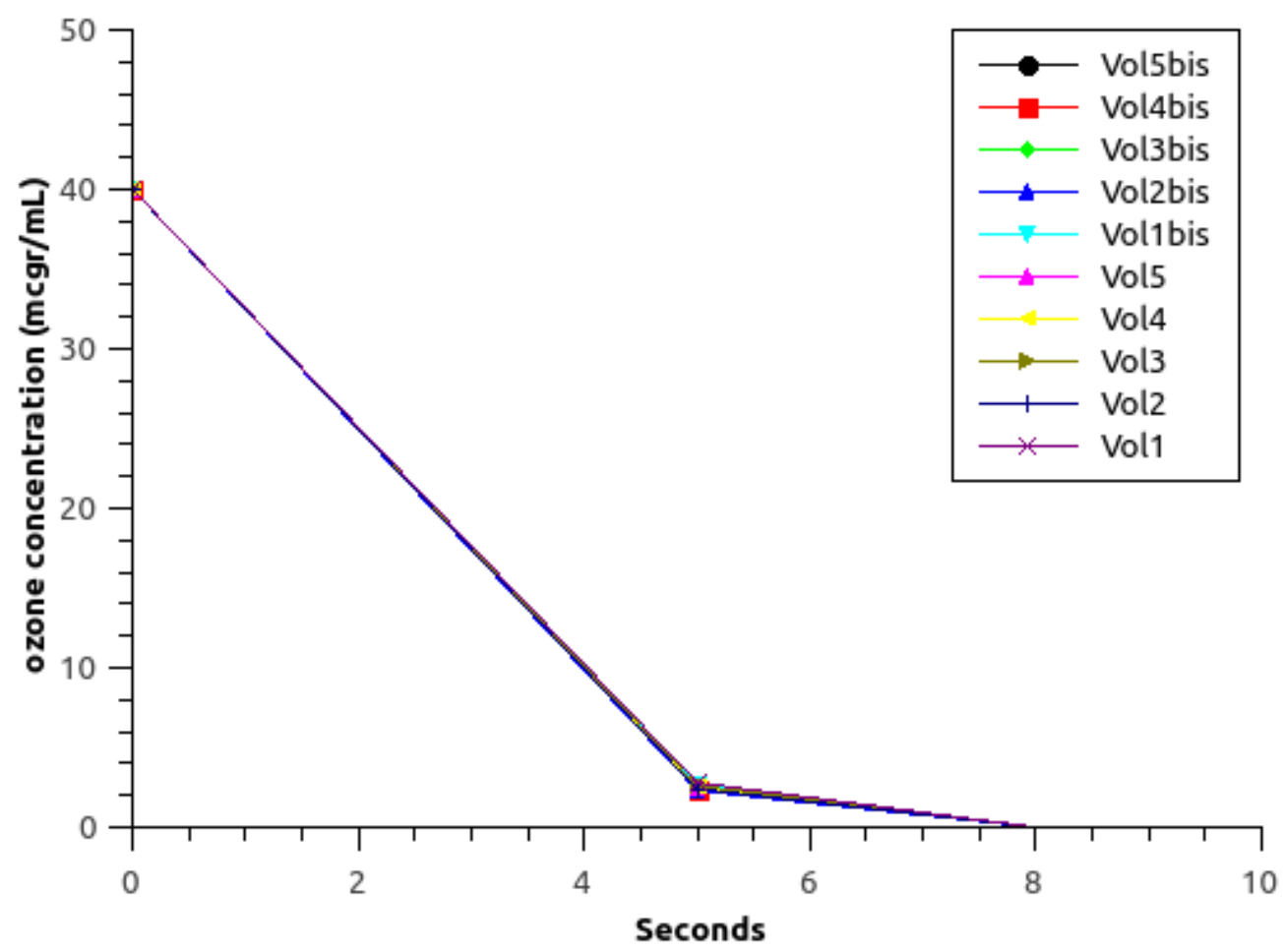

Figure 3. Ozone absortion for $40 \mu \mathrm{gr}(\mathrm{mL}$ of ozone concentration. 


\section{Ozone absortion}

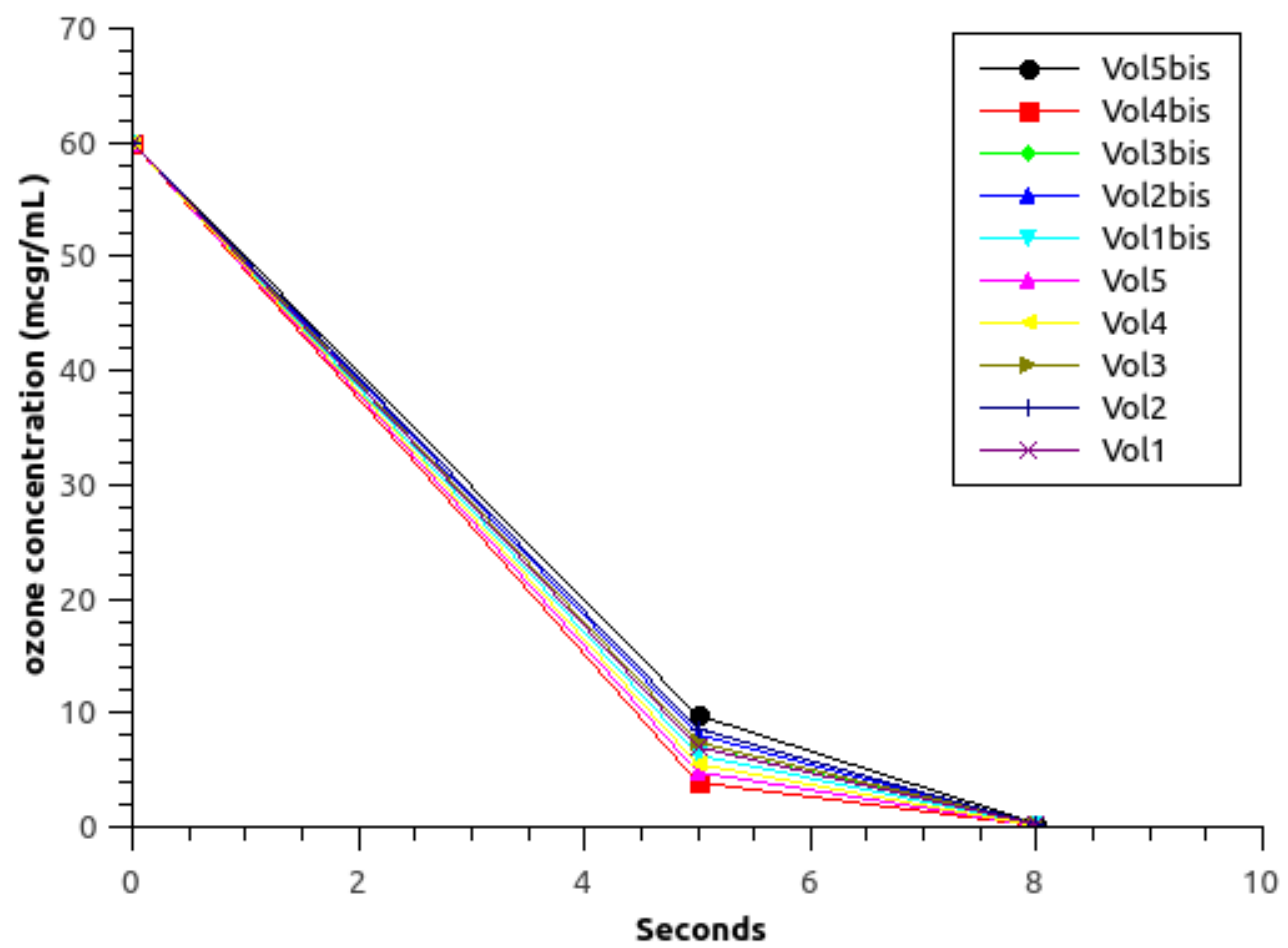

Figure 4. Ozone absortion for $60 \mu \mathrm{gr} / \mathrm{mL}$ of ozone concentration.

The linear regression analysis shows that a theoretical calculation for 80 $\mu \mathrm{gr} / \mathrm{mL}, 99.65 \%$ will react with the blood within 8 seconds (Figure 5). We could even think of adding 2 more seconds to be sure that even for $80 \mu \mathrm{gr} /$ $\mathrm{mL}$ concentration, 10 seconds is enough to allow all the ozone react with the blood.

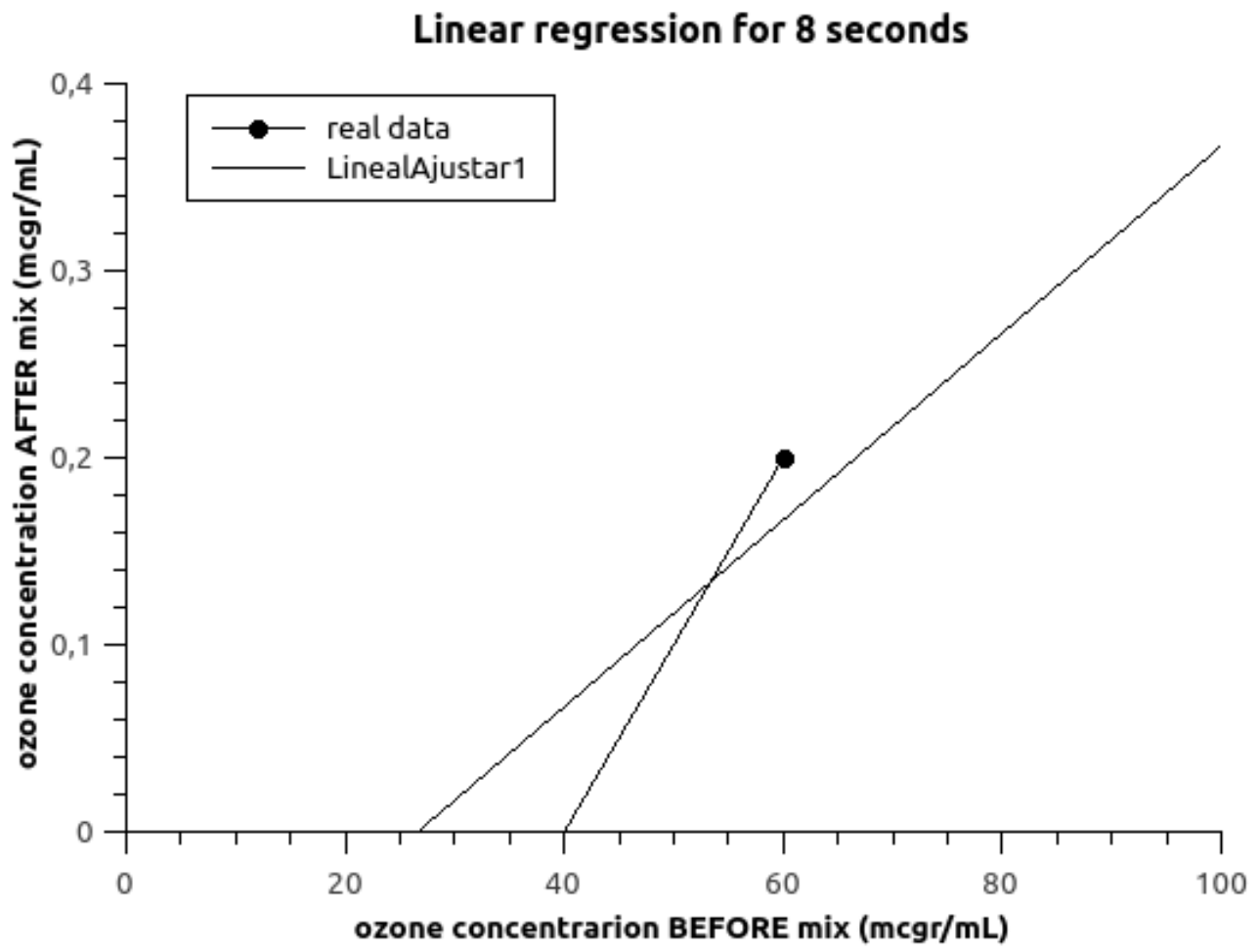

Figure 5. Linear regression analysis. 


\section{Conclusions}

In this basic experiment, we can scientifically asses that 10 seconds of mixing time is the optimal time. We could even use 5 seconds for $40 \mu \mathrm{gr} / \mathrm{mL}$ and lower concentrations.

Anyhow, we need to test the real mixing time with a real model under real conditions, because this experiment is just a call to face scientifically this undetermined variable in the SIEVO technique.

\section{References}

1. Menéndez-Cepero $S$, León-Fernández OS, Calunga-Fernández JL, Copello-Noblet M, Weiser WT. Advances of Ozone Therapy in Medicine and Dentistry. La Habana: Palcograf; 2016.

2. Viebhan-Haensler R. The use of ozone in medicine. 5th edition. Iffezheim: ODREI-Publishers; 2007.

3. Borrelli E. Manuale pratico di grande e piccola autoemoterapia ozonizzata. [Practical handbook for small and great ozonized autohemotherapy ] Second edition. Italy: UNI-Service; 2007.

4. Bocci V. Ozone. A new medical drug. Second edition. Dordrecht: Springer; 2011.

5. Gomez Moraleda, M. PhD Thesis on Cinética de las Reacciones del Ozono en Régimen de borboteo y su Aplicación. [Kinetics of Ozone Reactions in Bubbling Regime and its Application] Centro Nacional de Investigaciones Científicas, Ciudad La Habana; 1983. 